\title{
STUDY OF SITE AND TYPE OF UNION OF BILIARY DUCTS
}

\author{
Leena Ammini Bhaskaran¹, Romi Sadanandan² \\ ${ }^{1}$ Assistant Professor, Department of Anatomy, Government Medical College, Thiruvananthapuram. \\ 2 Professor and HOD, Department of Anatomy, Government Medical College, Thiruvananthapuram.
}

\section{ABSTRACT}

\section{BACKGROUND}

The study of angle of union of biliary ducts is of great importance to the hepatobiliary surgeons. The union of cystic and common hepatic duct can be angular, spiral or parallel. The site of union can be average, high or low.

\section{MATERIALS AND METHODS}

Study was conducted on 250 specimens (Cadaveric, Autopsy and Foetal) in Government Medical College, Thiruvananthapuram, for 2 years. Site and type of union was observed.

\section{RESULTS}

Type 1 or angular union of ducts was most common. Low union of ducts was seen in majority.

\section{CONCLUSION}

Knowledge of anatomy of biliary ducts is important for hepatobiliary surgeons, as the variations are very common and can cause complications during surgery.

\section{KEYWORDS}

Cystic, Common Hepatic, Duct, Type, Site.

HOW TO CITE THIS ARTICLE: Bhaskaran LA, Sadanandan R. Study of site and type of union of biliary ducts. J. Evolution Med. Dent. Sci. 2017;6(62):4534-4538, DOI: 10.14260/Jemds/2017/981

\section{BACKGROUND}

The right and left hepatic ducts arising from the liver unite as the common hepatic duct, joins the cystic duct at an acute angle to form the common bile duct. The bile duct approaches the pancreatic duct; unite to form the hepatopancreatic ampulla, which opens on the summit of major duodenal papilla.

According to the type of junction formed by common hepatic duct and cystic duct, there may be greater or lesser risk of injury of these structures during surgical interventions or pathological processes. In normal individual, anomalies in this region does not create any medical emergencies, but it may produce significant complications following the surgeries pertaining to this region.

The manner of junction of cystic and common hepatic duct was cited in LH Blumgart's ' 'Surgery of liver, biliary tract and pancreas.' The modes of union may be 3 types- angular, parallel and spiral. Angular union is most frequent and is found in $75 \%$ patients. The cystic duct may run a parallel course to common hepatic duct in $20 \%$ with connective tissue ensheathing both ducts. Finally, cystic duct may approach common bile duct in a spiral fashion. It could be anterior spiral or posterior spiral. Variations of gallbladder, hepatic, cystic and bile ducts were reported by Johnston EV and

\section{Financial or Other, Competing Interest: None.}

Submission 28-06-2017, Peer Review 22-07-2017,

Acceptance 28-07-2017, Published 03-08-2017.

Corresponding Author:

Dr. Leena Ammini Bhaskaran,

Aswathy, Koora-40,

Koottamvila Road,

Vattiyoorkavu P. O.

Trvandrum-13.

E-mail: ableena@gmail.com

DOI: $10.14260 /$ jemds $/ 2017 / 981$
Anson $\mathrm{BJ}^{2}$ in 1952 after detailed dissections of hepatoduodenal ligament in thirty-five cadavers. Julian A Sterling 3 in 1955 studied the angle of union of cystic and common hepatic ducts.

In some people, there is low union of cystic and common hepatic duct. As a result, bile duct is short and lies posterior to first part of duodenum or even below it. When there is low union, two ducts may be joined by fibrous tissue making surgical clamping of cystic duct difficult without injuring common hepatic duct. Occasionally, there is high union of cystic and common hepatic ducts near porta hepatis.

Anatomical study of junction of cystic duct and common hepatic duct in 33 foetuses was done by Santiago MS, Santiago $\mathrm{TS}^{4}$ et al in 2003. Keizman D, Shalom MI5 et al in 2006 studied angulation of common bile duct, which predisposes to recurrent symptomatic bile duct stones after endoscopic stone extraction. Gulzari Lal Nigam ${ }^{6}$ et al in 2014 studied the biliary ducts in 59 individuals undergoing hepatobiliary surgery and in 30 cadavers.

\section{MATERIALS AND METHODS}

Study design was descriptive. The number of specimens required was calculated based on the formula-

$$
\mathrm{n}=\frac{1.96^{2} \times \mathrm{p} \times \mathrm{q}}{\mathrm{L}^{2}}
$$

The least variation observed was in angulation of ducts, which is $37 \%$ according to the study of Johnston EV and Anson $\mathrm{BJ}^{2}$ in 1952 in "Variations in the formation and vascular relations of bile ducts."

$$
\begin{gathered}
\mathrm{L}=37 \times 20 / 100=7.4 \\
\mathrm{n}=\frac{1.96^{2} \times 37 \times 63}{7.4 \times 7.4} \sim 180
\end{gathered}
$$


The foetuses with anomaly was 10 out of 15 as per the study. "Extrahepatic biliary passages: an anatomical study in full-term human foetuses" by Girijakumari $\mathrm{K}^{7}$ in 1990 . This comes to $66 \%$.

$\mathrm{L}=66 \times 20 / 100$.

$$
\mathrm{n}=\frac{1.96^{2} \times 66 \times 34}{13.2 \times 13.2} \sim 50
$$

The study was conducted on 20 cadavers in Anatomy Department, 160 autopsies in Department of Forensic Medicine in Government Medical College, Trivandrum. Around 50 foetal specimens were obtained during foetal autopsies conducted by Pathology Department. Abdominal wall was reflected in cadavers. Peritoneum is incised similarly and abdominal cavity exposed. Greater omentum was identified. Coeliac trunk and origin of right hepatic artery was noted. Stomach was removed by double ligatures. Careful dissection of hepatobiliary region was carried out. Measurements were done using vernier calipers with an accuracy of $0.01 \mathrm{~mm}$. Angles were measured using protractor.

Types of Union of Cystic and Common Hepatic Ducts were Classified as-

Type 1 - Normal angular union.

Type 2A - Joins anterior to common hepatic duct.

Type 2P - Joins posterior to common hepatic duct.

Type 3 - Short parallel $10-25 \mathrm{~mm}$.

Type 4 - Long parallel $>25 \mathrm{~mm}$.

Type 5 - Anterior spiral union.

Type 6 - Posterior spiral union.

\section{RESULTS}

Average angle of union of cystic and common hepatic duct in present study was $42.5 \pm 0.89$ degrees (Table 1). Angle between hepatic ducts was $111.1 \pm 4.82$. Angle between common bile duct with vertical was $36.7 \pm 0.57$ degrees.

\begin{tabular}{|c|c|c|c|c|}
\hline Angle & Average & Value & & Sd \\
\hline Angle 1 & $60-120$ & 111.1 & + & 4.82 \\
\hline Angle 2 & $0-94$ & 42.5 & + & 0.89 \\
\hline Angle 3 & $16-52$ & 36.7 & + & 0.57 \\
\hline \multicolumn{5}{|c|}{ Table 1. Angle between Ducts } \\
\hline
\end{tabular}

Angle 1- Angle between right hepatic duct, left hepatic duct. Angle 2- Angle between cystic duct and common hepatic duct. Angle 3- Angle between common bile duct with vertical.

\begin{tabular}{|c|c|c|}
\hline Union Right and Left Hepatic Ducts & Number & $\mathbf{\%}$ \\
\hline Extrahepatic & 5 & 2.2 \\
\hline Intrahepatic & 225 & 97.8 \\
\hline Total & $\mathbf{2 3 0}$ & $\mathbf{1 0 0 . 0}$ \\
\hline Table 2. Union of Right and Left Hepatic Ducts \\
\hline
\end{tabular}

Majority of hepatic ducts had intrahepatic union.

\begin{tabular}{|c|c|c|}
\hline $\begin{array}{c}\text { Site and Type of Union of Cystic } \\
\text { and Common Hepatic Duct }\end{array}$ & Number & $\mathbf{\%}$ \\
\hline Average, Type 1 & 48 & 20.8 \\
\hline Average, Type 2A & 6 & 2.6 \\
\hline Average, Type 2P & 1 & .4 \\
\hline Average, Type 3 & 6 & 2.6 \\
\hline
\end{tabular}

\begin{tabular}{|c|c|c|}
\hline Average, Type 4 & 4 & 1.7 \\
\hline Average, Type 5 & 8 & 3.5 \\
\hline Average, Type 6 & 8 & 3.5 \\
\hline High, Type 1 & 22 & 9.5 \\
\hline High, Type 2A & 1 & .4 \\
\hline High, Type 2P & 3 & 1.3 \\
\hline High, Type 3 & 5 & 2.2 \\
\hline High, Type 4 & 4 & 1.7 \\
\hline High, Type 5 & 5 & 2.2 \\
\hline High, Type 6 & 5 & 2.2 \\
\hline Low, Type 1 & 53 & 23 \\
\hline Low, Type 2A & 9 & 3.9 \\
\hline Low, Type 2P & 7 & 3.0 \\
\hline Low, Type 3 & 7 & 3.0 \\
\hline Low, Type 4 & 3 & 1.3 \\
\hline Low, Type 5 & 11 & 4.8 \\
\hline Low, Type 6 & 12 & 5.6 \\
\hline NIL & 1 & .4 \\
\hline Very High Type 1 & 1 & .4 \\
\hline Total & $\mathbf{2 3 0}$ & $\mathbf{1 0 0 . 0}$ \\
\hline Table 3. Site and Type of Union of \\
Cystic and Common Hepatic Duct \\
\hline
\end{tabular}

\begin{tabular}{|c|c|c|}
\hline Site of Union & Number & \% \\
\hline Average & 81 & 35.2 \\
\hline High & 46 & 20 \\
\hline Low & 102 & 44.4 \\
\hline NIL & 1 & .4 \\
\hline Total & $\mathbf{2 3 0}$ & $\mathbf{1 0 0 . 0}$ \\
\hline
\end{tabular}

Table 4. Level of Union of Cystic and Common Hepatic Duct

Low union of cystic duct and common hepatic duct was more common followed by average union. The least was low union of ducts.

\begin{tabular}{|c|c|c|}
\hline Type of Union & Number & $\mathbf{\%}$ \\
\hline Nil & 1 & .4 \\
\hline Type 1 & 123 & 53.5 \\
\hline Type 2A & 16 & 7 \\
\hline Type 2P & 11 & 4.8 \\
\hline Type 3 & 18 & 7.8 \\
\hline Type 4 & 11 & 4.8 \\
\hline Type 5 & 24 & 10.4 \\
\hline Type 6 & 26 & 11.3 \\
\hline Total & $\mathbf{2 3 0}$ & $\mathbf{1 0 0 . 0}$ \\
\hline
\end{tabular}

Table 5. Type of Union of Cystic and Common Hepatic Duct

Various types of union of biliary ducts are shown in Table 5. Angular union of ducts was most common.

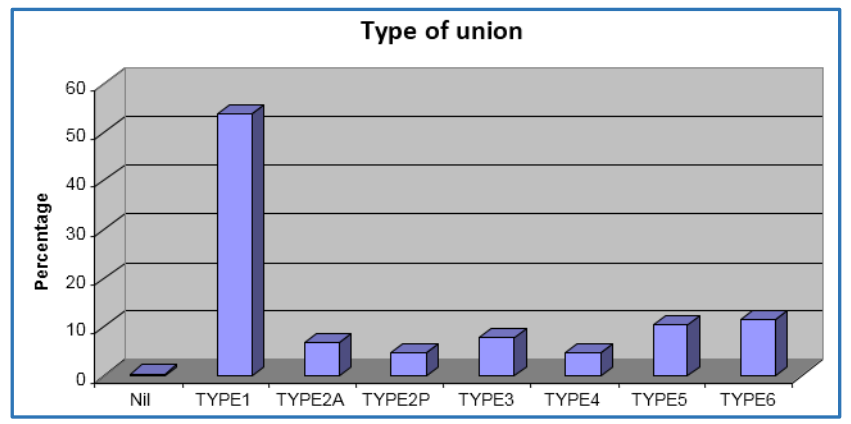

Chart 1. Type of Union of Cystic and Common Hepatic Duct 


\begin{tabular}{|c|c|c|c|c|c|c|c|c|c|}
\hline \multirow[t]{2}{*}{ Duct } & & \multirow[t]{2}{*}{ Number } & \multirow[t]{2}{*}{ Mean } & \multirow[t]{2}{*}{ SD } & \multirow{2}{*}{$\begin{array}{l}\text { Standard } \\
\text { Error }\end{array}$} & \multicolumn{2}{|c|}{$\begin{array}{l}\text { 95\% Confidence } \\
\text { Interval for Mean }\end{array}$} & \multirow[t]{2}{*}{ Minimum } & \multirow[t]{2}{*}{ Maximum } \\
\hline & & & & & & Lower Bound & Upper Bound & & \\
\hline \multirow{5}{*}{$\begin{array}{c}\text { Left } \\
\text { Hepatic } \\
\text { Duct }\end{array}$} & Nil & 1 & 1.200 & & & & & 1.2 & 1.2 \\
\hline & Average & 81 & 1.578 & .6971 & .0775 & 1.424 & 1.732 & .2 & 2.6 \\
\hline & Low & 103 & 1.651 & .7204 & .0710 & 1.511 & 1.792 & .5 & 3.6 \\
\hline & High & 46 & 1.513 & .6797 & .1002 & 1.311 & 1.715 & .3 & 3.4 \\
\hline & Total & 231 & 1.596 & .7023 & .0462 & 1.505 & 1.687 & .2 & 3.6 \\
\hline \multirow{5}{*}{$\begin{array}{c}\text { Right } \\
\text { Hepatic } \\
\text { Duct }\end{array}$} & Nil & 1 & .800 & & & & & .8 & .8 \\
\hline & Average & 81 & 1.269 & .5463 & .0607 & 1.148 & 1.390 & .2 & 2.5 \\
\hline & Low & 103 & 1.384 & .6014 & .0593 & 1.267 & 1.502 & .2 & 3.2 \\
\hline & High & 46 & 1.235 & .5693 & .0839 & 1.066 & 1.404 & .4 & 3.2 \\
\hline & Total & 231 & 1.312 & .5770 & .0380 & 1.237 & 1.386 & .2 & 3.2 \\
\hline \multirow{5}{*}{$\begin{array}{l}\text { Cystic } \\
\text { Duct }\end{array}$} & Nil & 1 & .000 & & & & & .0 & .0 \\
\hline & Average & 81 & 2.127 & 1.0090 & .1121 & 1.904 & 2.350 & .3 & 4.0 \\
\hline & Low & 103 & 2.434 & .9968 & .0982 & 2.239 & 2.629 & .6 & 4.2 \\
\hline & High & 46 & 1.907 & .9034 & .1332 & 1.638 & 2.175 & .4 & 4.2 \\
\hline & Total & 231 & 2.211 & 1.0094 & .0664 & 2.080 & 2.342 & .0 & 4.2 \\
\hline \multirow{5}{*}{$\begin{array}{c}\text { Common } \\
\text { Hepatic } \\
\text { Duct }\end{array}$} & Nil & 1 & .000 & & & & & .0 & .0 \\
\hline & Average & 81 & 2.021 & 1.0092 & .1121 & 1.798 & 2.244 & .4 & 4.0 \\
\hline & Low & 103 & 2.193 & 1.0433 & .1028 & 1.989 & 2.397 & .4 & 5.0 \\
\hline & High & 46 & 1.798 & .9919 & .1462 & 1.503 & 2.092 & .4 & 5.0 \\
\hline & Total & 231 & 2.045 & 1.0343 & .0681 & 1.910 & 2.179 & .0 & 5.0 \\
\hline \multirow{5}{*}{$\begin{array}{l}\text { Common } \\
\text { Bile } \\
\text { Duct-Total }\end{array}$} & Nil & 1 & 3.900 & & & & & 3.9 & 3.9 \\
\hline & Average & 81 & 6.867 & 3.5510 & .3946 & 6.081 & 7.652 & 1.1 & 10.8 \\
\hline & Low & 103 & 6.804 & 3.2240 & .3177 & 6.174 & 7.434 & 1.0 & 11.4 \\
\hline & High & 46 & 7.215 & 3.8037 & .5608 & 6.086 & 8.345 & 1.3 & 11.5 \\
\hline & Total & 231 & 6.895 & 3.4482 & .2269 & 6.448 & 7.342 & 1.0 & 11.5 \\
\hline & & able 6. & npariso & between & vel of $U n$ & of Ducts and & ength of Ducts & & \\
\hline
\end{tabular}

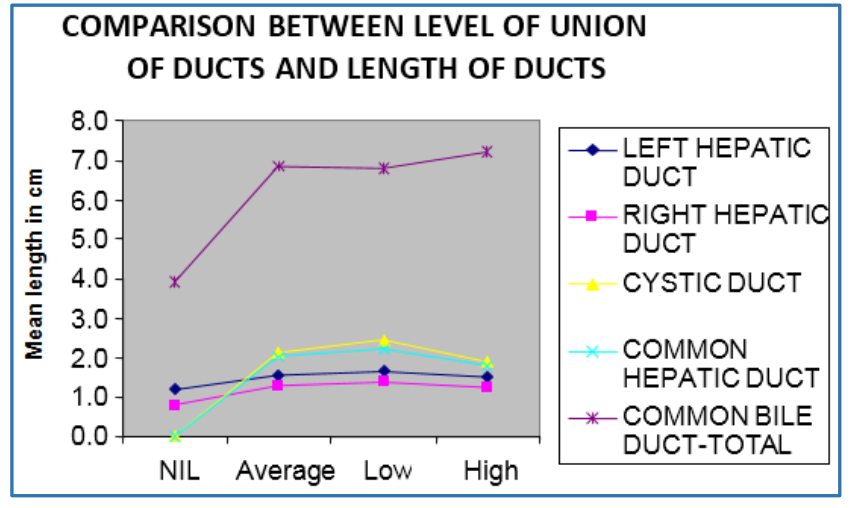

Chart 2

There is no significant difference in the mean values of the above variables among those with average type and high type. However, mean length of cystic duct and common hepatic duct was significantly higher for low type when compared to high type (See Table 11). Common bile duct was longer in high type comparatively.

Similarly, there was no significant difference in the mean values of these variables among average type and low type.

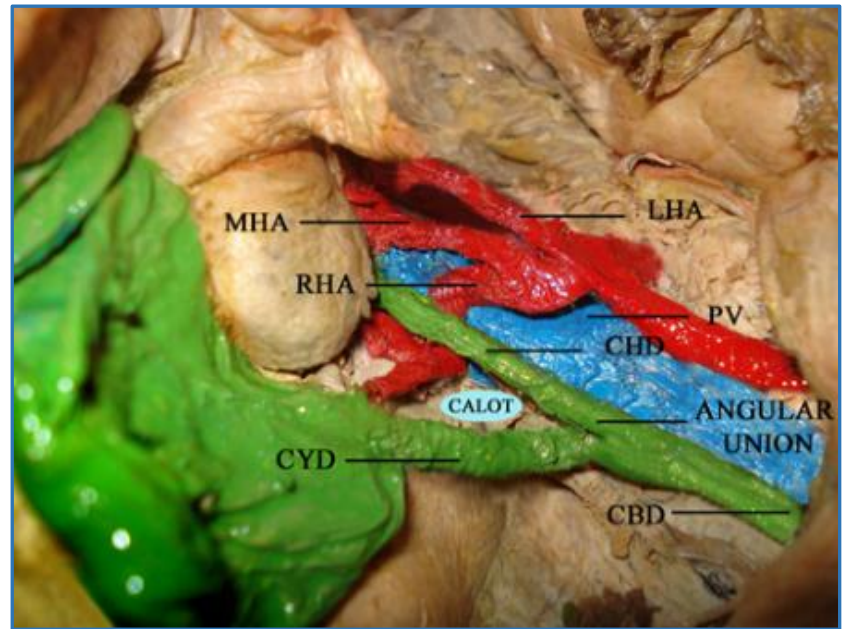

Figure 1. Middle Hepatic Artery, Average, Angular Union of Cystic Duct with Common Hepatic Duct

MHA - Middle hepatic artery.

CHA - Common hepatic artery. 


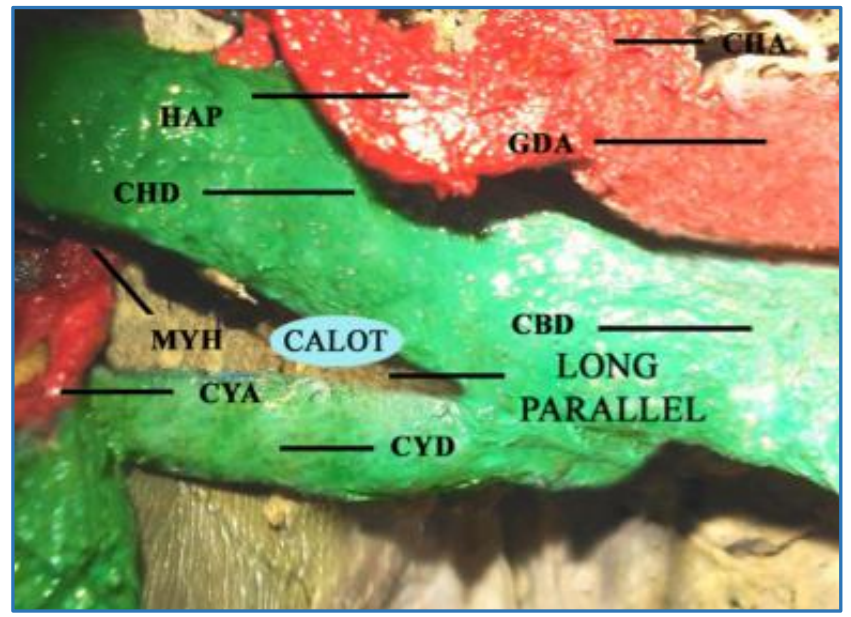

Figure 2. Low and Long Parallel Type of Union of Cystic and Common Hepatic Ducts, Moynihan's Hump

HAP - Hepatic artery proper.

CHA - Common hepatic artery.

GDA - Gastroduodenal artery.

CALOT - Calot's triangle.

MYH - Moynihan's hump.

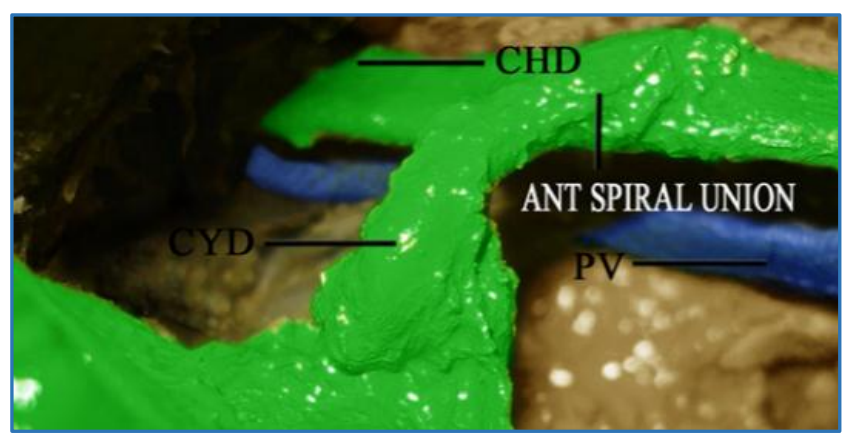

Figure 3. Anterior Spiral Type of Union of Cystic and Common Hepatic Ducts

PV - Portal vein.

Ant. Spiral Union - Anterior spiral union.

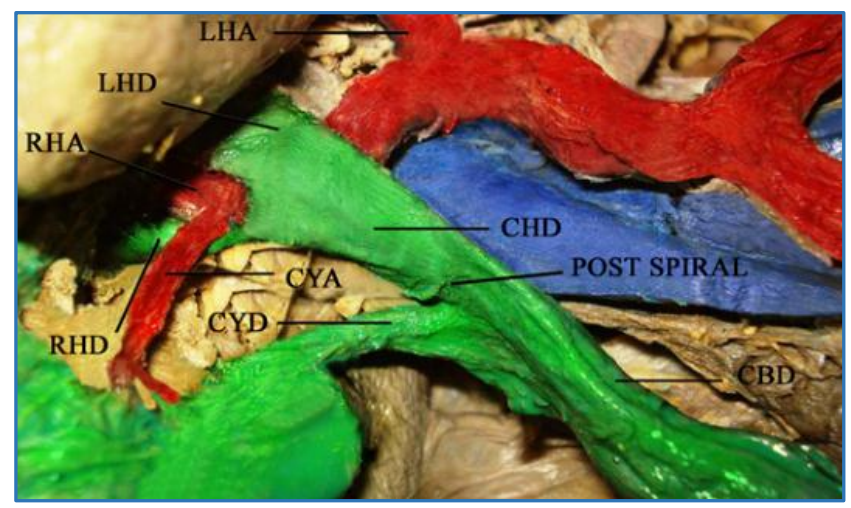

Figure 4. Right Hepatic Artery between Right Hepatic and Left Hepatic Ducts, Posterior Spiral Union of Cystic and Common Hepatic Ducts, Cystic Artery Anterior to Right Hepatic Duct

LHA $\quad$ - $\quad$ Left hepatic artery.

POST SPIRAL - Posterior spiral union.

\section{DISCUSSION}

The angle of union of cystic and common hepatic duct is highly variable. Average angle of union was $42.5 \pm 0.89$ degrees (Table 1). Congenital absence of cystic duct was reported in a 1-year-old male child with agenesis of gallbladder.

Common variations in union of cystic and common hepatic ducts are angular, parallel and spiral. Parallel was classified into short parallel, where the 2 ducts join together for $10-25 \mathrm{~mm}$ and then unite. Long parallel type is where cystic and common hepatic ducts join together for more than $25 \mathrm{~mm}$ and then unite.

Normal angular union (Fig. 1) of cystic duct joining the right side of common hepatic duct at acute angle was seen in $65.4 \%$, which was less than reported by Moosman and Coller, ${ }^{8}$ Johnston EV,2 Julian A Sterling, ${ }^{3}$ Tamol Limthanakhom ${ }^{9}$ and Santiago, ${ }^{4}$ but more than Ruge, Kunze and Eisendrath. ${ }^{10}$ Angular union was $94 \%$ in the study by Gulzar Lal Nigam. ${ }^{6}$ Angular junction with the anterior aspect of common hepatic duct (Fig. 1) was found in $6.9 \%$ and posterior aspect of common hepatic duct in $4.8 \%$. This was more compared to Hayes, ${ }^{11}$ who found $0.75 \%$ anterior and $0.5 \%$ posterior union of ducts.

Short parallel $(5-7 \mathrm{~cm})$ type of union was more common, which agrees with Thompson. ${ }^{12}$ Short parallel $(10-25 \mathrm{~mm})$ was seen in $4.3 \%$ which was less compared to Moosman (15.2\%), whereas long parallel $(>25 \mathrm{~mm})$ was seen in $8.2 \%$ which was more compared to Moosman ${ }^{8}$ (4.4\%). In the long parallel type if cystic duct is ligated too close to the common hepatic duct, it can undergo strictures or narrowing at this site.

Total parallel ducts noted in our study was $12.55 \%$, which was more than Tamol Limthanakhom ${ }^{9}-8.3 \%$, Gulzar Lal Nigam $^{6}-4 \%$ and less than Johnston EV ${ }^{2}-20 \%$, Ruge $-29 \%$, Eisendrath $-17 \%$, Santiago $4-29 \%$ and Hand ${ }^{13}-25 \%$.

Anterior spiral union (Fig. 3) was seen in $10.44 \%$ in the present study, more than Moosman and Coller (4\%) and posterior spiral (Fig. 4) in $11.3 \%$ which was more compared to Moosman and Coller $^{8}(1.2 \%)$. Spiral union in present study (both anterior and posterior) was $21.7 \%$, which was more than Hand $14-10 \%$, Moosman and Coller ${ }^{8}-5.2 \%$, Johnston EV 2 $-17.1 \%$, Kunze $-0 \%$, Julian A Sterling $3-8 \%$, Tamol Limthanakhom ${ }^{9} 6.3 \%$, Gulzar Lal Nigam ${ }^{6}-8 \%$ and less than Ruge $-38 \%$. Our study agrees with McWhorter ${ }^{15}$ and Thompson, ${ }^{14}$ in that posterior spiral union is more common than anterior spiral union.

Site of joining of cystic duct at the anterior aspect of common hepatic duct (type $2 \mathrm{~A}$ and type 5 ) was $16.5 \%$ in the present study, which was higher when compared to $4.2 \%$ Tamol $^{9}$ and $1.5 \%$ by Hayes. ${ }^{13}$ The present study reported $11.3 \%$ having posterior junction with the common hepatic duct, which was also greater than that observed by $(0 \%)$ Tamol $^{9}$ and (1\%) by Hayes. ${ }^{13}$

Variations in the position of junction of cystic and common hepatic ducts were studied. The insertion was found to be average (Fig. 1) type in $35.1 \%$, less than $45.2 \%$ by Santiago MS, high type in $19.9 \%$, less than $29 \%$ by Santiago MS and low type (Fig. 2) in $44.6 \%$ which was more than $25.8 \%$ by Santiago 4 MS. Among the anatomical variations, low union was most common in the present study which disagrees with Santiago MS who found that average insertion was most common. 
Low insertion of cystic duct was associated with high rate of common bile duct stone formation. Failure to identify a low insertion of cystic duct may result in technical difficulties during ERCP procedures.

The length of cystic and common hepatic duct was greatest in low union, intermediate in average union, least in high union and length of common bile duct was maximum in high union, least in low union of ducts which strongly agrees with Santiago ${ }^{4}$ MS.

Intrahepatic union (97.8\%) of right hepatic and left hepatic ducts was more common in the present study. This agrees with Cole and Associates with 90\% intrahepatic union, but disagrees with Thompson who reported 91\% extrahepatic union. According to study by Gulzari Lal Nigam, all union were extrahepatic. ${ }^{3}$

\section{CONCLUSION}

The anatomy of the extrahepatic biliary apparatus is highly variable and some of these variations and anomalies can be problematic for surgeons during surgical procedures such as laparoscopic cholecystectomy, liver resection and living donor transplantation. Surgery if not done carefully result in major complications such as leakage of ducts or atrophy of liver. Therefore, it is important to have a thorough knowledge in successful detection and recognition of such anatomic variations, thereby decreasing morbidity and mortality rates during hepatobiliary surgery.

\section{REFERENCES}

[1] Blumgart LH, Fong Y. Surgery of the liver and biliary tract. $3^{\text {rd }}$ edn. Vol 1, WB Saunders, London 2000:1639715.

[2] Johnston EV, Anson BJ. Variations in the formation and vascular relationship of the bile ducts. Surg Gynaec Obstet 1952;94(6):669-86.

[3] Sterling JA. The biliary tract. Williams and Wilkins 1955:46-56.

[4] Santiago MS, Santiago TS, Melo VA, et al. Anatomic study of variations in the position of the junction of the cystic and common hepatic ducts in fetuses. Acta Cir Bras 2003;18(1).
[5] Keizman D, Shalom MI, Konikoff FM. An angulated common bile duct predisposes to recurrent symptomatic bile duct stones after endoscopic stone extraction. Surg Endosc 2006;20(10):1594-9.

[6] Nigam GL, Lalwani R, Babu CSR, et al. Surgical anatomy of sub-hepatic biliary system. JASI 2014;63:48-51.

[7] Girijakumari K. Extrahepatic biliary passages: an anatomical study in full term human foetuses. University of Kerala 1990:35-48.

[8] Moosman DA, Coller FA. Prevention of traumatic injury to the bile ducts; a study of the structures of the cystohepatic angle encountered in cholecystectomy and supraduodenal choledochostomy. Am J Surg 1951;82(1):132-43.

[9] Limthanakhom T, Khamanarong K, Bhudhisawasdi V. The anatomical variations of cystic duct in northeastern Thai population. The Thai Journal of Surgery 2005;26(3):73-7.

[10] Eisendrath DN. Anomalies of the bile ducts and blood vessels. JAMA 1918;71(11):864-7.

[11] Hayes MA, Goldenberg IS, Bishop CC. The developmental basis for bile duct anomalies. Surg Gynaec Obstet 1976;107(4):447-56.

[12] Thompson IM. On the arteries and ducts in the hepatic pedicle: a study in statistical human anatomy. Univ of California Pub Anat 1933;1:55-160.

[13] Hand BH. Anatomy and function of the extrahepatic biliary system. Clin Gastroenterol 1973;2(1):3-29.

[14] McWhorter GL. A new method of gallbladder dissection with a consideration of the surgical anatomy. Surg Gynaec Obstet 1923;36:256-63.

[15] Cole WH. Congenital anomalies of the bile ducts and adjacent blood vessels. Surg Gynaec Obstet 1948;87(1):111-2. 